\title{
CANTO E ESPETÁCULO NA TRAGÉDIA GREGA: AS CENAS FINAIS DE HIPÓLITO DE EURÍPIDES
}

\author{
Fernando Brandão dos Santos*
}

RESUMO: I want to present here one of the plays studied in my doctorate, which had as theme the poetry (the song) and the spectacle in Greek tragedy, with Euripides in focus of the presented reflections. In this present article, I detach the relation of the prologue scene (vv. 1-120) consisting of a monologue uttered by Aphrodite (vv. 1-57), followed by a coral song to Artemis lead by Hippolytus (vv. 58-71), a monologue of Hippolytus (a prayer to Artemis) and a dialogue of Hippolytus with a servant (vv. 73120 ) in contrast to the final scenes - forth and last episode (vv. 1153-1267); the last stasimon, a hymn to Aphrodite sung by the chorus of Troizen married women (vv. 1268-82), followed by the exodus (vv. 1283-1466).

PALAVRAS-CHAVE: Eurípides, Hipólito, Canto, Espetáculo, Tragédia Grega.

O Hipólito foi apresentado em 428 a. C., dez anos depois da Alceste, obtendo o primeiro lugar nos concursos dramáticos, numa das raras vitórias de Eurípides ${ }^{1}$. Entre as duas estão Medéia, de 431; Os Heraclidas, entre 430 e 427; e, após o Hipólito, Andrômaca por volta de 426 a $424^{2}$. Eurípides havia apresentado uma peça anteriormente, da qual esta seria uma revisão, já que o Hippólytos Kalyptómenos teria sido rejeitado pelo público, porque na primeira versão Fedra se lançava aos pés de Hipólito, rogando-lhe seu amor. Ao que tudo indica, Fedra de Sêneca segue muito mais de perto a primeira versão, da qual não temos senão fragmentos ${ }^{3}$. Assim, o Hipólito é uma reescritura, uma reelaboração de uma peça já apresentada ${ }^{4}$. É uma pena que não tenhamos a primeira versão, para uma apreciação realmente mais efetiva do modo de composição e o que realmente os autores levavam em conta quando refaziam seus textos.

No prólogo temos a presença de um semi-coro de caçadores acompanhando Hipólito (vv. 57-72), reaparecendo no terceiro estásimo (vv. 1102-1110; vv. 1118-

\footnotetext{
* Professor de Língua e Literatura Gregas da Universidade Estadual Paulista (UNESP), Campus de Araraquara.

Vide Lesky, 1976, p. 178.

Para a datação das peças, estamos seguindo Romilly, 1982, pp. 186-87; cf. também Segal, 1993, pp. xi-xv.

Vide Snell, 1967, pp. 23-46, especialmente p. 28: "Because Hippolytos veiled himself when Phaedra made him her shameless offer. To be sure, Seneca does not mention the veiling, and he has padded the scene with much bombastic rhetoric but there can be no serious doubt that the structure of the scene and the character of Phaedra are taken over from first Hippolytos, because it is precisely this scene that gives rige to the indignation about Phaedra's shameless (and a shameless Phaedra is certain not Sophoclean)". Barrett (1964, p 16) alerta para o fato de que, embora Sêneca adapte suas peças a partir de originais áticos, tem o hábito de divergir bastante dos modelos com liberdade.

Vide Pickard-Cambridge (1969, p. 99): "In the fifth century the only performances of old plays (with an exception to be noticed,) were presentations of unsuccessful plays in a revised form - of comedies perhaps more frequently than of tragedies, though Euripides certainly revised and re-produced his Hippolyus, and possibly other plays". As outras peças de Eurípides que teriam recebido uma reescritura, não chegaram até nós, Autolycus e Phrixus; porém, como anota Picakrd-Cambridge, as evidências não são satisfatórias (ibid., nota 6).
} 
1130). O coro definitivo da peça, composto por mulheres de Trezena, ofereceria uma certa dificuldade, pois, depois da chegada de Teseu, mesmo conhecendo a verdadeira motivação do suicídio de Fedra, cala-se em relação aos acontecimentos presenciados, sem interferir em nada para que o jovem seja inocentado de alguma forma da grave e falsa acusação deixada por Fedra. A cena do kommós de Teseu com o coro (vv. 811884) começa quando o corpo de Fedra é trazido para fora do palácio sobre o ekklýklema, o que, sem dúvida, aumenta o tom patético da peça. Outra cena importante é o debate entre pai e filho, culminando no exílio de Hipólito (vv. 902-1101). O silêncio do coro, fundado em um juramento feito a Fedra (vv. 712-14), - com nuances diferentes do juramento feito por Hipólito à ama (vv. 601-615), - é compensado por sua interessante interferência do ponto de vista do espetáculo: no párodo, anuncia a estranha doença de Fedra (vv. 121-175); no primeiro estásimo, canta o poder de Eros (vv. 525-564); no segundo estásimo, completamente mergulhado nas revelações de Fedra e na recusa veemente de Hipólito, com o seu desejo de fuga e agitação emocional, o coro antecipa o desfecho trágico de Fedra; com a entrada de Teseu em cena, após a morte de Fedra, a peça perde um pouco de seu andamento dramático; no terceiro estásimo, o coro de mulheres alternaria seu canto com o semi-coro de jovens que acompanham Hipólito em seu desterro (vv. 1102-1150).

A peça termina sob a intervenção de Ártemis, cuja entrada em cena é antecedida pelo quarto estásimo, um hino a Cípris e a Eros (vv. 1268-1282). Com isso temos uma espécie de cena especular refletindo o que foi apresentado no prólogo com Afrodite abrindo a peça com seu monólogo, seguida da entrada de Hipólito cantando à Ártemis. Ártemis, tal como Afrodite, é implacável. A dor de Teseu, a dor de Hipólito moribundo em cena, fazem parte já do patético - não há mais ação possível para reverter o que se consumou ao longo dos episódios. Fedra não mais é mencionada ou lembrada no final. Os homens ficam abandonados em suas dores mortais. Tudo isso é oferecido aos olhos e aos ouvidos do espectador à maneira didática de Homero, adaptado ao nómos e ao êthos próprios dos atenienses:

\begin{abstract}
Ouvindo e assistindo às peças encenadas, eles reconheciam e absorviam um comentário corrente a seu próprio nómos e êthos. Realizando essa função, o drama grego permanece fundamentalmente didático quanto a seu propósito. Seus muitos compositores - um título mais adequado que o de autores - aplicavam sua arte à combinação de educação oral com entretenimento oral (Havelock, 1996, p 276).
\end{abstract}

\title{
PRÓLOGO: vv.1-120
}

Segundo G. M. Grube, o prólogo, do ponto de vista dramático, aparentemente não teria sido bem organizado pelo poeta, porque necessita de um semi-coro que se desfaz quando o coro propriamente dito se instala na orquestra. Compõe-se de três cenas: o monólogo de Afrodite, que talvez apareça na primeira cena da peça num theologeion $^{6}$ (vv. 5-56), um dos recursos materiais para a encenação da intervenção de um deus em cena, num plano mais alto que o dos atores; Hipólito e um semi-coro de caçadores cantam interlúdio lírico (vv. 57-72) seguido do recitativo de Hipólito (vv. 73-

\footnotetext{
5 Para um estudo sobre o prólogo de Hipólito, ver Santos, 2000, pp. 7-14. Os textos citados seguem a edição de Barrett (1964) e são traduzidos por mim, salvo indicado em contrário.

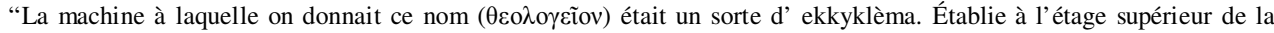
skènè (problablement au-dessus de la porte royale), elle consistait, à ce qu'on croit, en une plate-forme roulante qui, sortant de l' interieur, s'avançait sur un balcon en saillie" (Navarre, 1895, p. 133). Porém a evidência do uso deste dispositivo no século V a. C. é ainda controvertida entre os estudiosos: cf. Taplin (1978, pp. 21-41) para a discussão das aparições de Afrodite e Ártemis no Hipólito.
}

Organon, Porto Alegre, n 49, julho-dezembro, 2010, p.219 - 238 
87); o diálogo entre Hipólito e um servidor (vv. 88-120). A presença deste semi-coro, seguido pela entrada do coro composto por mulheres casadas de Trezena, que entoam o párodo e se instalam na orquestra, tem embaraçado alguns estudiosos da peça. G. M. Grube, por exemplo, afirma:

\begin{abstract}
O Hipólito oferece o paradoxo de um herói masculino, o próprio Hipólito, com um coro principal feminino. E aqui podemos observar novamente quanto a primeira parte da peça contava para determinar a composição desse coro. A cena em que Fedra relutantemente confessa seu amor por seu enteado teria sido impossível diante de um grupo de homens, nem poderia ela esperar nenhuma simpatia deles. Depois de sua morte, entretanto, homens teriam sido mais apropriados, pois, então, é Hipólito que necessita de apoio. Na verdade, porque nossa simpatia está imediatamente empenhada no interesse da mulher apaixonada, podemos sentir que era ele, e não Fedra, que necessitava do coro desde o começo. Isto, entretanto, não teria sentido para os gregos. Pode haver pouca dúvida de que a simpatia deles estaria com Hipólito, e que toda a arte de Eurípides era necessária, e um coro feminino, para fazê-los ver o ponto de vista de Fedra. A falta de equilíbrio, mais acentuada para nós, ele tentou remediar ao introduzir um coro secundário de caçadores no prólogo para cantar o hino a Ártemis, e parece provável que este coro de Hipólito reapareça mais tarde para juntar-se aos louvores de seu senhor (1973, p. 102).
\end{abstract}

O mesmo contraste entre coro e protagonista se verifica na Alceste, que tem um coro composto por velhos de Feres. G. M. Grube não leva em consideração a tensão dramática que se pode extrair dos contrastes e as ambigüidades que tal procedimento pode gerar. Como se percebe também, G. M. Grube está pensando unicamente na ação dramática da peça e não nos elementos que compõem o espetáculo. Aqui no Hipólito, a presença dos caçadores que acompanham o protagonista ilustra mais a descrição de seu modo de vida, relacionado às atividades de Ártemis, e auxilia-nos a construir a personagem em cena. Não se trata aqui de empatia ou não com o herói central da peça. A presença do coro de mulheres enfatiza, de fato, a simpatia que ao longo da peça o autor desenvolve no público em relação ao sofrimento de Fedra, e marca mais acentuadamente o contraste com o herói, que, de certa forma, vai ficando cada vez mais só em seu sofrimento.

Dos elementos do espetáculo, primeiramente devemos considerar o espaço cênico em que a ação se vai desenrolar. Afrodite, abrindo a peça, segundo as convenções teatrais do século V a.C., aparece sobre o palácio de Teseu. Esse palácio está situado em Trezena. Diante dele se vê uma estátua de Afrodite, colocada próxima à porta (v. 101) e possivelmente uma outra estátua, ou, como prefere W. S. Barrett (1964, p. 154), um altar dedicado a Ártemis, sem local claramente definido no texto em que o jovem deposita uma coroa. Do ponto de vista da ação dramática, se é uma estátua ou um altar de Ártemis não faz muita diferença. Teríamos apenas um elemento visual diferente, mas sem o comprometimento da ação. O importante é reter que a presença de ambas as deusas está marcada cenicamente e o será também dramaticamente. Ao longo da peça, essas duas deusas, cada uma por seu turno, apresentar-se-ão como forças antagônicas, cujos representantes no mundo dos mortais serão Fedra e Hipólito. Estamos, então, diante do palácio de Teseu em Trezena, ante cuja fachada se vê uma estátua de Afrodite e um altar (ou outra estátua) de Ártemis. Observemos, então, que há uma combinação de signos diferentes para referendar a ação dramática que toma corpo na seqüência dos episódios. No final da peça (a partir do v. 1330), seria a aparição de Ártemis ex-machina?

Assim, a peça apresenta-nos o confronto de duas forças antagônicas. De um lado, Afrodite, que aparece cenicamente apenas no monólogo do prólogo, expõe toda a exuberância do poder sexual a ela atribuído pela tradição mítica. $O$ efeito de suas palavras, porém, vai ser desenvolvido ao longo da peça e lembrado pelas diversas 
personagens. Do outro, Ártemis é apresentada como a deusa da caça e da castidade. O confronto que se vai ver em cena é uma pequena parte, por assim dizer, desse confronto universal de forças divinas que, de alguma forma, se opõem.

Fedra aparece como um instrumento fundamental nos planos de Afrodite:

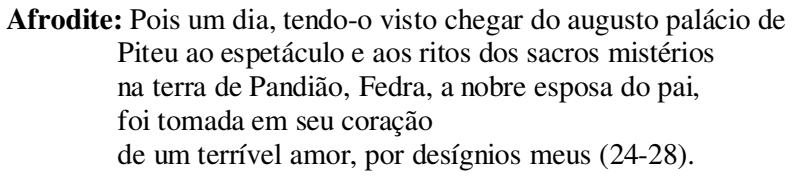

E é através de sua paixão pelo enteado que a ação dramática propriamente dita se desenrolará diante dos olhos do público. A morte de Fedra também é inevitável para a realização total dos desígnios de Afrodite: "ela é insigne, mas mesmo assim deve morrer/Fedra!"' (47-48), diz a deusa.

Hipólito aparece como a expressão máxima da adoração à deusa Ártemis: sua dedicação exclusiva, embora contestada pelo servo (sobretudo vv. 113-120), por Teseu (vv. 948-49) não é recusada pela deusa de sua devoção (v. 1333).

O monólogo de Afrodite é a mola propulsora de toda a composição do espetáculo. Sua fala é duplamente didática. Em primeiro lugar, fornece ao público as informações necessárias para o desenrolar da trama, isto é, antecipa os acontecimentos, estabelecendo as bases sobre as quais a ação dramática vai se desenvolver, e para a economia do espetáculo teatral, situa o público quanto às personagens e mesmo quanto ao espaço cênico. Colocando-se num presente, cujo futuro há de rapidamente se cumprir, sua voz é mais forte do que um oráculo vagamente anunciado, como temos, por exemplo, no Filoctetes, de Sófocles.

Nesta intervenção, primeiramente Afrodite identifica-se, anunciando seu nome e os limites de seu poder (vv. 1-5). Venerada por todos, exceto por um cidadão de Trezena, o filho da amazona, Hipólito (vv. 10-11). A acusação de Afrodite não é um mero capricho, o jovem Hipólito afirma que ela é a pior dentre as divindades:

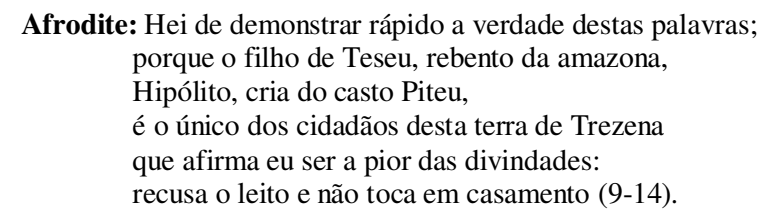

Afrodite, assim, compõe para o público a figura do jovem que em seguida deve ocupar a cena. A atenção do jovem dirige-se a outra divindade, Ártemis, antagonista de Afrodite, justamente naquilo que a caracteriza, a castidade (já assinalada no epíteto de

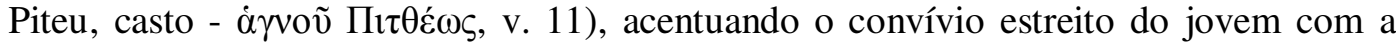
virgem filha de Zeus (15-19). Embora Afrodite, no projeto de destruir o jovem, afirme

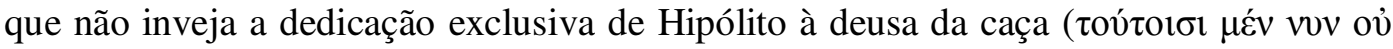

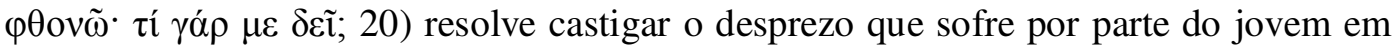

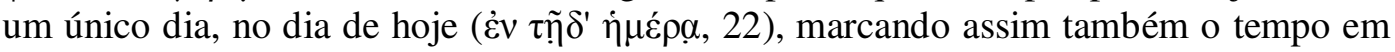
que a ação dramática deve transcorrer.

$\mathrm{Na}$ verdade, sua decisão, dentro do que podemos chamar macro espaço da peça, isto é, dentro das ações que excedem o dia de hoje, já está em curso (v. 24 e seq.). A tragédia de Hipólito revela-se para o público no mesmo dia em que as decisões da deusa se cumprirão: Hipólito será atingido pelos votos a que Teseu tem direito, recebidos de 
Posídon (vv. 43-46). A morte de Fedra também é necessária ao terrível plano da deusa o que não é estranho para a religiosidade grega.

A segunda cena deste prólogo começa a partir do anúncio da entrada em cena de Hipólito. Afrodite faz seu pronunciamento sobre um theologeion, colocado provavelmente acima do palácio de Teseu, acima de sua estátua em uma das laterais do proscênio. Essa sua fala, com uma métrica próxima à da prosódia comum ao ateniense, é interrompida por modulações de um canto coral dos caçadores liderados por Hipólito, homenageando Ártemis ${ }^{7}$ :

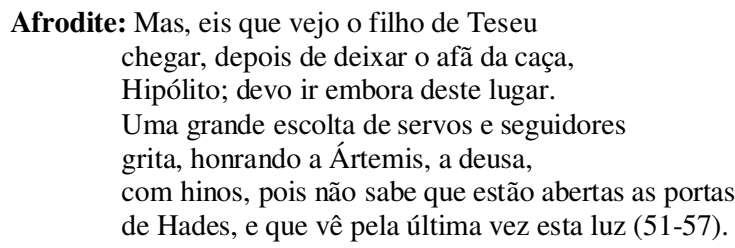

Assim, dentro do próprio prólogo a ação começa a se desenvolver. O que Afrodite falou passa a ser encenado no palco, e com isso também o programa estabelecido, consumando-se de uma maneira inevitável, irreversível. Todos, a partir da entrada do jovem em cena, se movem com a idéia de estar realizando o melhor. A ama, por exemplo, em sua tentativa de persuadir Hipólito a aceitar o amor de Fedra, tem a pretensão de salvar sua senhora da morte. Mas o resultado de sua ação é o oposto do esperado, revelando-se desastroso, por complicar ainda mais a situação moral da rainha. Como notou B. M. W. Knox, "em nenhuma outra tragédia grega a predeterminação da ação humana, feita por um poder externo, é tão enfaticamente clara" (1983, p. 312). Teseu, em sua decisão de amaldiçoar o filho, sem antes procurar saber claramente a respeito dos fatos comete um grande erro, uma $\alpha \mu \alpha \rho \tau i ́ \alpha \nu \mu \varepsilon \gamma \alpha ́ \lambda \eta \nu$ moldes estabelecidos por Aristóteles na Poética, cujo reparo se dá apenas com a intervenção da própria Ártemis, que faz com que Hipólito perdoe o pai alguns segundos antes de morrer em seus braços (vv. 1430-36).

Mas, se de um lado temos a predeterminação de Afrodite, imutável, por outro, Eurípides pinta com cores bem fortes a característica obstinada do jovem em sua recusa. O espetáculo confirma totalmente as palavras da deusa. A entrada em cena de Hipólito cantando um hino a Ártemis, com seu séquito de caçadores, provoca a saída de Afrodite ${ }^{8}$ : "Segui cantando, segui,/a filha de Zeus, a celestial Ártemis,/ a que se preocupa conosco" (58-60).

O semi-coro, composto por companheiros de Hipólito, então, dá continuidade à canção. Louis Méridier (1956, p. 31) chama a atenção para esse semi-coro acessório, remetendo-nos para as Eumênides de Ésquilo, em que também aparece um semi-coro a acompanhar a deusa num cortejo de sacerdotisas de Atena (cf. vv. 1032-47). Esse pequeno interlúdio coral, simples, em termos de espetáculo é eficiente. Mescla-se às últimas palavras de Afrodite, marcando assim o contraponto paradoxal entre as duas divindades:

Semi-coro: Soberana, soberana venerandíssima,

7 T. B. L. Webster aponta: "The Hippolytos of 428 is more complicated. In the prologue Hippolytos leads on the subsidiary chorus of huntsmen and sings an aeolo-choriambic hymn to Artemis. This is in dance time; he certainly sings the first three lines and probably sings the rest with them, but it is curious that there is no clear differentiation between leader and chorus" (1970, p. 147). No entanto, a prece a Ártemis é feita só por Hipólito. Isso não indicaria sua liderança sobre os caçadores?

Barrett, em seu comentário, esclarece: "(sung by Hippolytos alone, exhorting the singers) begins with an anhoplion, a colon which has affinities both with aeolic and with dactyl metres; here it develops into two short dactylic cola, hemiepe" (1964, pp. 167-68).

Organon, Porto Alegre, nº 49, julho-dezembro, 2010, p.219 - 238 


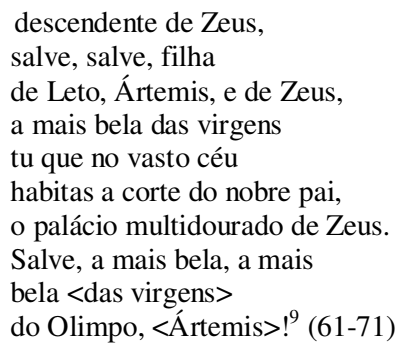

Mesmo sem a posse da partitura musical e da partitura coreográfica dessa interrupção musical, a métrica e o dialeto dórico ${ }^{10}$ são marcas acentuadas de um outro registro lingüístico, que, com certeza, não passaria despercebido ao público ateniense. Além do mais, note-se que a cena compõe um ritual religioso, suscitando no público outras emoções, desconhecidas para nós, meros leitores. Portanto, a presença de um semi-coro a acompanhar Hipólito extrapola a falta de equilíbrio dramático da peça; ao contrário, começa a ilustrar em forma de canto-dança-ritual o que Afrodite acabara de anunciar. E isso não poderia ser feito pelo coro de mulheres. Interpondo-se entre a fala de Afrodite, a prece que Hipólito irá dedicar a sua dileta deusa e o diálogo seguinte com o servo, advertindo-o sobre os perigos da parcialidade por sua devoção exclusiva, este canto dramaticamente talvez não seja necessário, não muda a ação em nada, mas tem uma função teatral muito clara: expor ao público os atos de Hipólito, sua negligência para com a mais poderosa dentre os deuses e os mortais. A oposição que se verifica em relação ao conteúdo, verifica-se também no nível de expressão. Eurípides não só acentua o aspecto dramático, mas sua composição da cena busca dar um passo a mais: a teatralização, ou seja, a encenação do que foi dito pela deusa. Nisso, o canto do semicoro torna-se vital para o espetáculo que o compositor quer nos fazer ver.

A prece de Hipólito acentua a estranheza da relação que mantém com sua dileta deusa (Cf. Vernant, 1973, 281-82). É uma continuidade do canto e revela uma idéia de pureza estranha ao homem comum do século $\mathrm{V}$ a. C.:

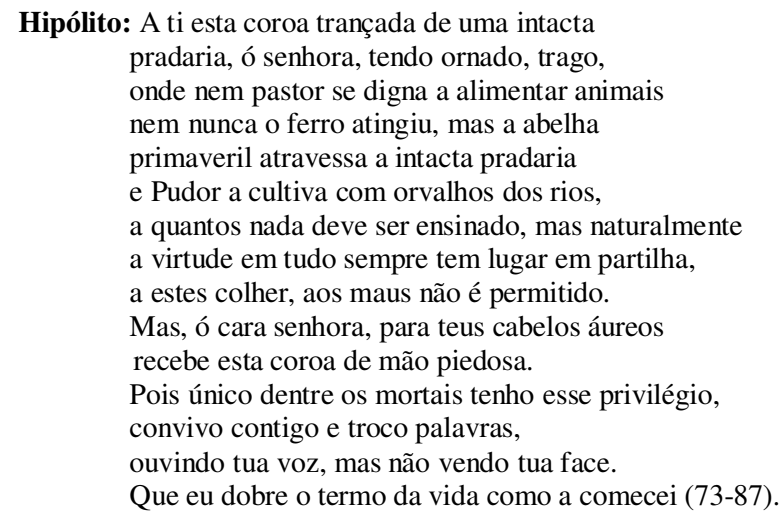

Durante esta prece, o elemento visual que se destaca é a coroa que o jovem traz em suas mãos e deposita na estátua de Ártemis: um objeto de cena que comporta outros signos além da homenagem devocional. A coroa é elaborada a partir de uma pradaria

9 Barrett não lê < também não lê a repetição. Aceitamos a leitura de Méridier (1956, p. 31), pois não consideramos um erro a repetição, já que se trata de uma peça cantada, havendo outras repetições que não são refutadas.

Para a discussão do dialeto dórico estilizado, usado nos cantos corais trágicos, cf. Webster, 1964, p. 111. 


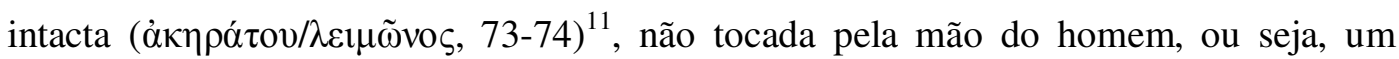
espaço selvagem. De lá de onde vêm os elementos que compõe a coroa, símbolo da castidade total do jovem; lá o aidós, como um jardineiro, cuida de plantas com o

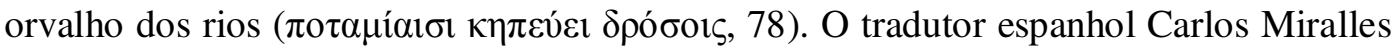
chama a atenção para a interpretação que se tem dado a esta prece de Hipólito: "esta primeira parte, com a descrição rápida da pradaria intacta, está com segurança esboçada sobre o modelo mítico da pureza original e inacessível, que na Grécia havia informado o relato mítico hesiódico à primeira idade do homem" (1977, p. 100). No entanto, não se encontram em Hesíodo referências a uma castidade ou pureza sexual como a que busca Hipólito aqui. Em Hesíodo, a castidade tem apenas o sentido de pureza física, limpeza, por ocasião da celebração do ato religioso, sendo assim temporária. Barrett (1964, p. 172) esclarece sobre a noção de pureza no século $\mathrm{V}$ a. C.: "requeria que o homem que entrasse em um lugar sagrado ou que participasse de um ritual sagrado deveria estar hagnós, mas essa hagneia era uma tarefa puramente formal de observar tabus, de evitar, ou purificar polução causada por coisas tais como sujeira física ou contato com algum aspecto de nascimento, sexo ou morte". Assim, a idéia de pureza moral é estranha ao culto grego até a época helenística ${ }^{12}$.

W. S. Barrett dá-nos uma pista melhor: é preciso buscar no século V a. C. as contrapartidas das crenças de Hipólito. As crenças órficas e talvez os cultos de mistério apresentem a seus seguidores uma proposta de pureza moral semelhante à que vemos nessa prece do jovem caçador. Mas Hipólito está alheio à sociedade em que vive. "Este jovem enérgico e intolerante construiu dentro de seu culto à virgem Ártemis um puritanismo estranho e exclusivo para si mesmo: a platéia ateniense, enquanto sente a beleza de seus ideais (o poeta cuidou disso), ao mesmo tempo há de sentir a estreiteza deles e há de achá-los excessivos e antinaturais" (1964, p. 172).

É interessante pensar na idéia de um mundo original oposto a um mundo de corrupção. Charles Segal vê que

\begin{abstract}
A pradaria não ceifada, numa perspectiva psicanalítica, simboliza também a nostalgia que Hipólito tem de uma união pre-edipiana com sua mãe, desejo este que se deve abandonar ou transformar para que o adolescente se torne um homem maduro. Uma união assim, caso se consuma, não pode conduzir a não ser ao desmembramento (simbólico) e à morte (1987, p. 166).
\end{abstract}

Note-se ainda que em toda a prece de Hipólito podem-se encontrar elementos

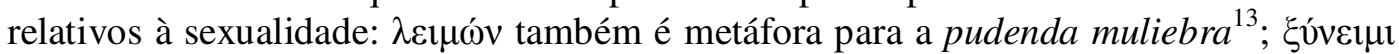
(v. 85) também é o verbo para descrever a relação íntima, portanto, também para designar a relação sexual. Em termos psicanalíticos, a recusa de Hipólito de cultuar Afrodite e a sua relação íntima com Ártemis podem ser entendidas como uma sublimação da sexualidade. No entanto, os gregos não tinham essa noção em seu imaginário, e o que o poeta destaca é a estranheza da relação de Hipólito com Ártemis, ímpar, afastada da religiosidade do homem comum, explorando assim as tensões dramáticas contidas na castidade e na exacerbação da sexualidade.

Mas essa recusa do jovem, apresentada desde o canto coral, louvando Ártemis, deusa da castidade por excelência, até a prece destaca-se mais quando um dos membros da comitiva chama-lhe a atenção. Em consonância com a voz de Afrodite, o criado

\footnotetext{
11 Na prece de Hipólito, o elemento úmido está ligado à pradaria intacta, isto é, não destruída, não atingida pela kńp, ao

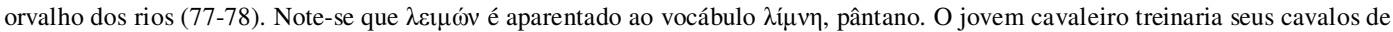
um pântano marinho, em Trezena, em que Ártemis Limnaia era cultuada.

12 Vide Segal, 1987, p. 185.

13 Cf. Eur. Ciclopes, 171, apud Liddell \& Scott, Greek-English Lexicon, Oxford, 1985, sub voc.
} 
estabelece um diálogo em que a idéia do nómos prevalece (v. 91), um costume estabelecido entre os mortais que consiste em respeitar os deuses em geral, sem preferência por um em detrimento de outro (v. 106). E não é gratuitamente que Eurípides faz um criado, saído do coro, apresentar, depois de Afrodite, uma advertência ao modo estranho de Hipólito se comportar diante das deusas, honrando uma, desprezando a outra ${ }^{14}$.

Assim, cenicamente confirma-se a fala de Afrodite, com uma encenação do que a deusa afirmara minutos antes. Sob este emblema termina o prólogo de Hipólito. Neste prólogo, Fedra só aparece na fala de Afrodite. Instrumento da vingança da deusa, Eurípides, hábil desenhista de estados emocionais, vai desenhar-lhe a figura a partir da entrada definitiva do coro, fazendo-a apresentar outras camadas do Aidós.

\section{AS CENAS FINAIS}

\section{Quarto episódio}

O quarto estásimo de Hipólito está colocado depois do quarto episódio que é constituído basicamente da fala de um mensageiro. Note-se que aqui o mensageiro é um dos companheiros de Hipólito e sua entrada é, como de praxe para os mensageiros, anunciada pelo corifeu: e agora, vejo este criado de Hipólito/com pressa avançar em direção ao palácio (1151-1152).

Ainda que se considere uma personagem secundária nas tragédias, o mensageiro com seu relato tem uma importância dramática considerável. Suas palavras ecoam ainda o projeto de Afrodite. À moda épica, o relato deste companheiro de Hipólito traz para a cena o terrível espetáculo da violência sofrida pelo jovem fora do espaço da ação dramática.

Como assina Shirley A. Barlow, num capítulo especialmente escrito para os mensageiros, "The Messanger Speech: Factual Landscapes", ao contrário dos cantos corais e monodias, o relato do mensageiro deve ser claro, objetivo, lógico e em ordem cronológica. Nele não encontramos revelações intuitivas, visões ou paixões incoerentes: "Pois em Eurípides uma coisa é certa. Devemos acreditar no mensageiro e não olhar além de seu relato, como olhamos além de uma monodia, para uma versão que é diferente ou menos preconcebida. Eurípides nunca permite que um mensageiro minta" (Barlow, 1986, p. 61). Para que sua fala seja efetiva, o mensageiro tem como instrumento a claridade das imagens relatadas, ainda que sejam coisas incríveis, mas que pela vivacidade do relato podem ser visualizadas (cf. p. 62). Todos esses elementos são encontrados no relato do mensageiro. Após um breve diálogo, em que se apresenta, passa a narrar os acontecimentos extra-cena, ou seja, do macrocosmo da ação.

Neste passo, cabe assinalar que Teseu, ainda convencido da culpa do filho, alegra-se em saber que seus votos foram cumpridos (v. 1169), mas depois do relato por, ter respeito aos deuses ( $\alpha i \delta o v ́ \mu \varepsilon v o \zeta / \theta \varepsilon o u ́ \varsigma)$ nem se alegra nem sofre (vv. 1258-60). O conteúdo do relato do mensageiro liga todos os pontos levantados durante a ação, porque daqui para frente não há mais ação propriamente dita. O que acontecer de novo, após o relato, é em função de um esclarecimento do que se passou.

A exemplo da ama em Alceste, o mensageiro "teatraliza" as falas de Hipólito: "Depois de um tempo, evitando os gemidos disse:/'Por que me agito com isso? Devo

\footnotetext{
14

Carlos Miralles (1977, p. 103) chama-nos a atenção para o valor cambiante do termo $\sigma \varepsilon \mu v o ́ \varsigma$ no diálogo entre o jovem e o servo: "Nótese cómo el sentido de $\sigma \varepsilon \mu v o ́ \varsigma$ varía, del que tine aquí y en el v. 94, en el v. 99 (cfr. v. 91, detalle que se pierde al traducir". O referido termo já aparece na fala de Afrodite (25), referindo-se às celebrações dos mistérios. O sentido, então do termo gravita entre o nosso "solene", "sagrado", "divino", referindo-se sobretudo ao universo religioso, e "soberbo", "majestático", "augusto", "orgulhoso", referindo-se a seres humanos e seus afazeres.
} 
obedecer às ordens de meu pai./Preparai os cavalos que trazem o jugo no carro,/criados. Pois já não tenho mais cidade"' (1181-84).

A ordem de Hipólito soa paradoxal, porque são esses cavalos que irão fazer cumprir seu destino, explicitado por seu nome. Mas a ironia maior aparece na prece que o mensageiro dirige a Zeus, depois do carro pronto: "Ó Zeus, que eu não mais exista, se sou um homem mau./Que meu pai saiba o quanto me desonrou,/quer eu tenha morrido quer esteja vendo a luz" (1191-93).

Com elementos próprios da teatralização, o mensageiro relata com detalhes

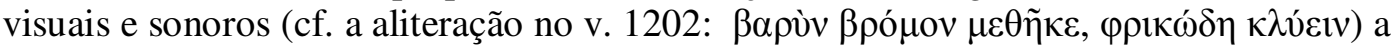
marcha violenta enfrentada por Hipólito contra as forças elementais que o voto de Teseu

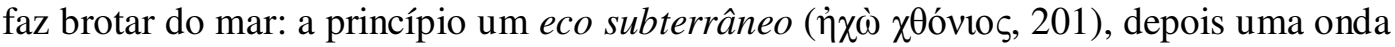

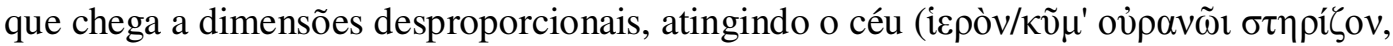

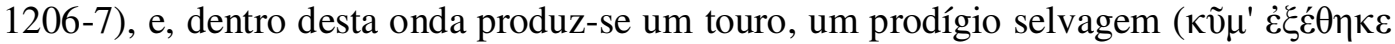

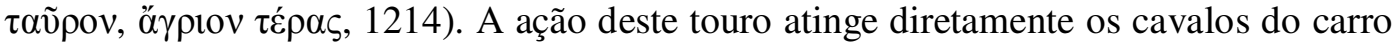
de Hipólito. A descrição do mensageiro contempla os mínimos detalhes de como Hipólito conduzia o carro, a reação dos cavalos, e o resultado fatídico (vv. 1215-1248).

Tanto o touro como o cavalo estão associados a Posídon e, por conseguinte, à sexualidade masculina ${ }^{15}$. A intervenção de Posídon, evocada nesta fala do mensageiro, ainda se relaciona com os domínios de Afrodite e a extensão de sua decisão.

O corpo de Hipólito, moribundo, deve ser trazido, por ordem de Teseu, que vê na desgraça um sinal dos deuses: "Trazei-o, para que, vendo-o com meus olhos,/ele que negou ter sujado minha cama, refutá-lo com palavras e com as desgraças das divindades" (1265-67).

É esse contexto que emoldura o quarto estásimo, uma pequena ode cantada pelo coro. Para W. S. Barrett, o poeta está conduzindo a simpatia do público em direção a Hipólito, já que toda a expectativa da peça agora recai sobre a entrada em cena do jovem moribundo, depois do relato aterrador do mensageiro:

\begin{abstract}
O mensageiro foi-se, e Teseu e Coro são deixados a sós; estamos esperando Hipólito aparecer e, enquanto esperamos, o Coro canta uma ode. Seu tema vem como um choque. Nossos pensamentos estão voltados à piedade por Hipólito, a uma tristeza indignada pela injustiça de seu fado; estamos dispostos a um lamento de protesto contra tal injustiça como a que tivemos na ode anterior (1102-1150). Ao invés disso, temos um hino a Afrodite, à própria deusa que provocou seu fado: um hino que celebra, com palavras não de medo nem de deprecação, mas com aceitação calma e homenagem sem questionamento, seu poder universal e irresistível (1964, p. 391).
\end{abstract}

Uma das vantagens da poesia dramática é a surpresa. A condução de nossa empatia na direção de Hipólito, agora que Fedra já morreu, é proposital. O público sabia que Hipólito deveria morrer em algum momento da peça, desde o prólogo, não há novidade nisso. Mas Eurípides é um hábil dramaturgo, e intencionalmente explora as possibilidades dramáticas. O cadáver de Hipólito poderia ser trazido inerte à cena, como o de Fedra. Não é isso que o poeta quis que seu público visse.

\title{
Quarto estásimo
}

A pequena ode a Cípris aqui tem, sim, a função de provocar um efeito de surpresa. O poeta não quer que apenas nos comovamos pela piedade banal, esperada, à qual ele mesmo nos conduziu. No prólogo, Cípris abre o espetáculo apresentando o programa da peça. Sua saída é provocada pelo canto de Hipólito e seus companheiros,

\footnotetext{
$15 \quad$ "The Bull, of course, is an obvious sexual symbol and, like the horse, is also associated with Poseidon (both bulls and
} horses are regularly sacrificed to him)" (Segal, 1986, p. 200).

Organon, Porto Alegre, $\mathrm{n}^{\circ}$ 49, julho-dezembro, 2010, p.219-238 
um canto religioso, solene, mas que, da perspectiva da deusa em cena, também é uma prova de sua afronta. Agora que todo seu plano está consumado, o coro entoa um hino em sua homenagem, reforçando os limites de seu poder, exatamente antes da entrada de Ártemis:

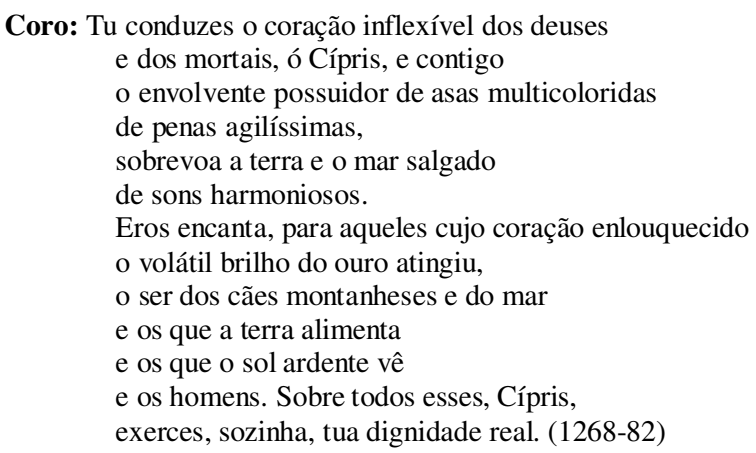

De certa forma ele conclui a ação dramática. Tudo o que tinha que acontecer, aconteceu. Não haverá mais novidades, novos acontecimentos, novas surpresas. As palavras do coro neste canto confirmam o poder absoluto de Afrodite, o tema central da peça. As personagens que ocuparam a cena, agora tornam-se anônimas e igualadas a

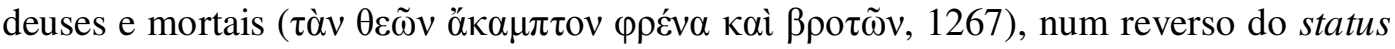

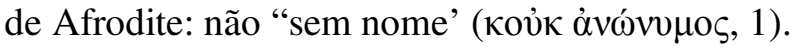

C. Segal aponta a dualidade da natureza de Afrodite:

Esta ambigüidade é aprofundada no realce sobre os pássaros e vôos, pois, anteriormente, também, a imagem de ave teve um significado ambíguo, expressando ambos, a esperança do homem escapar para um mundo de beleza não perturbada (v. 731 e seq.) e a realidade da morte (veja v.

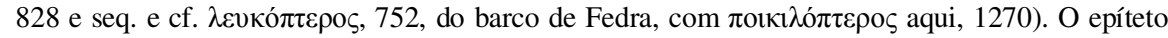

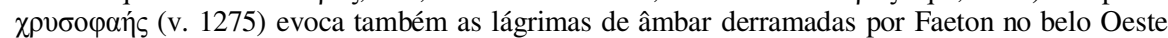

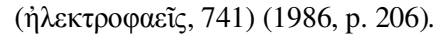

O que vimos, em cena até aqui, foi a atuação do poder absoluto de Afrodite. A ambigüidade deste canto torna-se mais evidente pelo espetáculo que se segue, quando, ex-machina, surge em cena Ártemis, numa inversão especular da cena do prólogo, em que, ao surgir o canto a Ártemis, Afrodite retira-se.

\section{Êxodo: vv. 1283-1466}

Aqui, no momento em que o poder soberano de Afrodite é exaltado em canto, Ártemis surge primeiramente off stage, destacando-se primeiramente sua $\mathrm{voz}^{16}$; e mesmo que surja ex-machina, tornando-se visível ao público sobre o palácio, sua aparição é sempre reforçada primeiro em termos acústicos ${ }^{17}$. Em nenhum momento o coro ou qualquer outra personagem alude a uma visão da deusa. Dirigindo-se diretamente a Teseu, que se manteve em cena durante o canto a Afrodite:

Ártemis: A ti, nobre filho de Egeu, ordeno que me ouças:

$\mathrm{Eu}$, a virgem de Letó, Ártemis, te falo. Teseu, por que te comprazes com isto, depois de matar teu filho de modo ímpio,

\footnotetext{
16 Para Barrett, Ártemis está sobre o palácio, ainda que Hipólito não possa vê-la, ao longo da cena (cf. (1964, pp. 395-96).

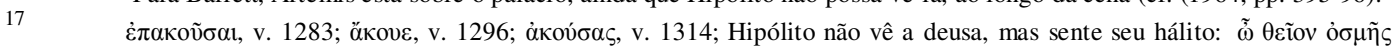

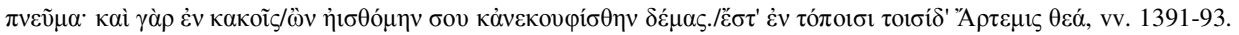




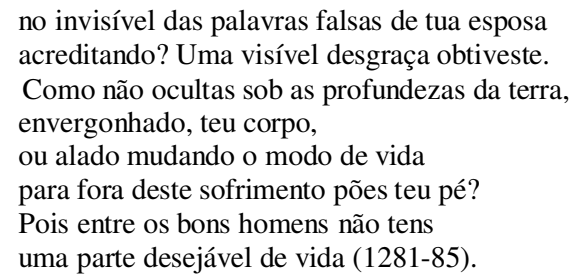

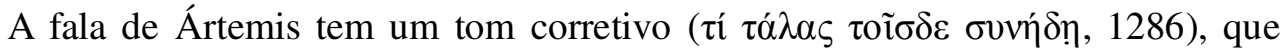

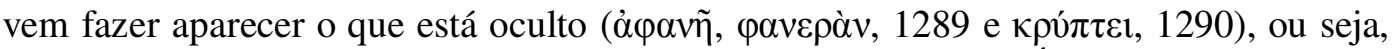
reverter o desequilíbrio gerado por Afrodite. Hipólito, esclarece Ártemis, agiu de modo

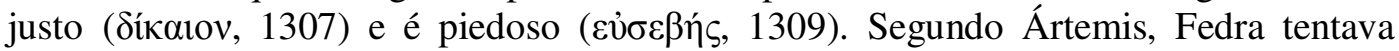
vencer Cípris com a razão ( $\gamma v \omega ́ \mu \eta !, 1304)$ e perdeu-se por causa da ama (1305). Mas o conjunto dos acontecimentos é resumido por Ártemis numa frase que nos faz lembrar Afrodite no prólogo (cf. 7-8): "Pois Cípris quis que acontecesse isso,/para satisfazer sua ira. Entre deuses o costume é esse" (1327-28).

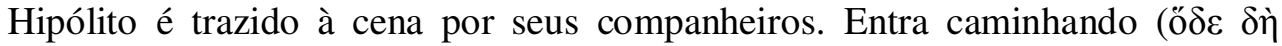

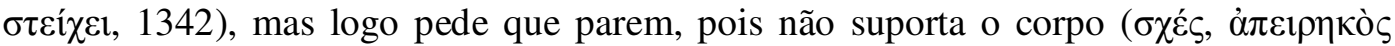
$\left.\sigma \tilde{\omega} \mu^{\prime} \alpha \dot{\alpha} \alpha \pi \alpha v ́ \sigma \omega, 1353\right)$. Hipólito dá uma série de instruções, para que os servidores encontrem uma posição que não o incomode (vv. 1354-1369), mas a partir do v. 1370, as dores ficam mais intensas, fato também indicado pela métrica e pelo registro lingüístico ${ }^{18}$. Ártemis dirige-se a Hipólito (vv. 1289-90), mas devido a seu estado, ou por Ártemis permanecer invisível, Hipólito não pode ver a sua deusa. Ele sente sua presença, de acordo com o que antes declarara (vv. 86-87): "Ah! perfume de hálito divino! Pois mesmo nos males em que/estou, sinto a ti e meu corpo é aliviado./ neste lugar Ártemis, a deusa" (1391-93).

O jogo entre o visível e invisível, encoberto e descoberto está prestes a se a acabar. Hipólito não vê a deusa, mesmo que ela esteja numa machina acima do palácio de Teseu, mas a deusa o vê ${ }^{19}$ :

Hipólito: Estás vendo, senhora, como estou, o miserável?

Ártemis: Vejo, mas não me é permitido derramar lágrima dos olhos (1395-96).

Aos deuses não é permitido chorar por um mortal. Mas Ártemis, após um breve diálogo com Hipólito, do qual Teseu participa também (vv. 1397-1415), proclama sua vingança (vv. 1420-22) e institui o ritual do corte de cabelo em oferenda a Hipólito, que deve ser feito antes do casamento pelas virgens de Trezena (vv. 1423-1430). Antes de se retirar, Ártemis reconcilia pai com filho e filho com pai (vv. 1431-1436). Tampouco os deuses podem presenciar a morte, que ela sabe estar próxima (vv. 1437-39).

Ártemis sai de cena, restando apenas pai e filho, no momento mais difícil para o homem, que é presenciar a morte. Em seu estudo sobre a pessoa na religião grega, JeanPierre Vernant, entre tantas outras reflexões de interesse, assim se pronuncia sobre esse momento particular da peça:

Logo que a deusa deixa Hipólito, ela o abandona diante da morte, não tem o direito de sujar o seu olhar com o espetáculo de um moribundo ou de um cadáver (v. 1437). Assim, no momento em que Hipólito teria mais do que nunca necessidade ao seu lado de uma presença divina, Ártemis afasta-se, retira-se neste universo divino que ignora tudo das realidades muito humanas do

18 Cf. Barrett (1964, pp. 405-409) para a análise métrica e comentários.

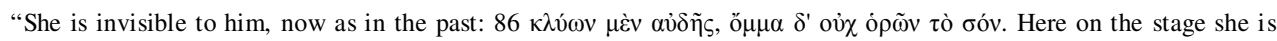
simply outside his field of vision (see on 1283); but that symbolizes readily enough the true invisibility that we must think of her as maintaining before him" (Barrett, 1964, p. 409).

Organon, Porto Alegre, $\mathrm{n}^{\circ}$ 49, julho-dezembro, 2010, p.219-238 
sofrimento, da doença e da morte. Se existe uma intimidade, uma comunhão com o deus, elas não poderiam situar-se no plano do que constitui para o indivíduo o seu destino pessoal, o seu status de homem. Na hora decisiva, não é Ártemis é Teseu - um Teseu arrependido, que é perdoado -, quem sustentará a cabeça de Hipólito e que recolherá o seu último suspiro" (1973, pp. 282-283).

A expectativa de Vernant em relação ao momento que ele julga ser mais necessária a presença de uma divindade, isto é, o momento da morte, tenta retratar mais uma expectativa comum na religiosidade mais próxima da piedade cristã, o que inexiste para os gregos. Na peça, acentuou-se mais o estranhamento pela proximidade e a intimidade de Hipólito com Ártemis do que o fato de ela o abandonar exatamente na hora da morte.

Hipólito, antes de morrer, perdoa o pai por sua morte, um gesto não apenas de piedade. Ao libertá-lo da responsabilidade por sua morte, libera-o de cumprir certos rituais de purificação que tinham o objetivo de aplacar o espírito do morto (vv. 1448$1451)^{20}$. Teseu não deve apenas recolher o último suspiro, mas também cobrir o rosto de Hipólito: "Minhas forças se esgotaram, pois morro, pai./Cobre meu rosto o mais rápido com véus" (1455-56).

A peça termina com o pai cobrindo o rosto do filho morto, num gesto teatral para assinalar a morte em cena, enquanto, reconhece o valor do filho (vv. 1459-60). O espetáculo, que se abriu com a voz de uma divindade soberana, termina com os lamentos e lágrimas de homens e com a lembrança dos males provocados por Cípris ( $\dot{s}$

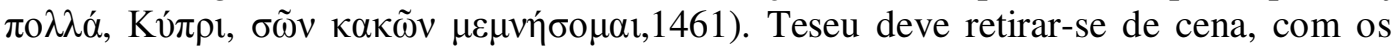
servos conduzindo o corpo de Hipólito para dentro do palácio, durante as últimas palavras do coro (vv. 1462-66), que também sai em seguida por um dos êxodos silenciosamente $^{21}$. O tom emocional deste final, semelhante ao de outras peças de Eurípides, é o da lamentação.

\section{À GUISA DE UMA CONCLUSÃO}

O canto e o espetáculo, no conjunto da peça, revelam a constatação do domínio absoluto de Afrodite sobre homens e deuses. Aparecendo apenas no prólogo, o efeito de sua força avança a cada novo movimento da peça de maneira calculada e efetiva revelando as tensões e as ambigüidades dos valores, das palavras e das ações humanas ${ }^{22}$. Ártemis, como força opositora da deusa da sexualidade, aparece primeiro no comportamento estranho e extremo de Hipólito. No final da peça, quando o projeto de Afrodite está consumado, Ártemis surge para restabelecer a ordem num mundo de desencontros dos homens, resultados sempre entre que se diz e o que se faz, entre o que se revela e o que se oculta, todos eles amplamente apresentados em cena, pontuados emocionalmente pelos cantos tanto do coro como dos atores. Os corpos de Fedra e de Hipólito agora estão cobertos, velados, fechados, contudo, revelam mais claramente a trágica fragilidade humana.

\section{BIBLIOGRAFIA}

\footnotetext{
20 "So in Attic Law the victim before his death could absolve the killer from the consequences of the killing (...)" (Barrett, 1964, p. 415).

21 Vide Barrett (1964, pp. 417-20) para as dificuldades desse texto final do coro.

22 Segal (1993, p. 144) observa: “All the characters' attempts at flight or purity, with their implicit aspiration toward transcending bodily nature, are subverted by the essential elements of the mortal condition in its physicality: constrictions by the seasonal rhythms of the earth in the need for 'Demeter's grain', sexuality, and death".
} 
BARLOW, Shirley A. The Imagery of Euripides. A study in the dramatic use of pictorial language. 2nd. Ed. Bristol: Bristol Classical Press, 1986.

BARRETT, 1964 = EURIPIDES. Euripides Hippolytos. Edited with introduction and Commentaries by W. S. BARRETT. Oxford: Clarendon Press, 1964.

DIGGLE, 1984 = EURIPIDIS. Fabulae (vol. I): Ciclops, Alcestis, Medea, Heraclidae, Hippolytus, Andromacha, Hecuba. Edidit James DIGGLE. Oxford: Clarendon Press, 1984.

GRUBE, G. M. A. The Drama of Euripides. London: Methuen \& Co., 1973.

HAVELOCK, Eric. A revolução da escrita na Grécia e suas conseqüências culturais. São Paulo/Rio de Janeiro: Editora Unesp/Paz e Terra, 1996.

KNOX, Bernard. The Hippolytos of Euripides. In: SEGAL, Erich (org.). Oxford Readings in Greek Tragedy. Oxford: University Press, 1983.

LESKY, Albin. A tragédia grega. São Paulo: Perspectiva, 1976.

MÉRIDIER, 1956 = EURIPIDE. Hippolyte, Andromaque, Hécube. Téxte établi et traduit par Louis MÉRIDIER. 2eme ed. Paris: Les Belles Lettres, 1956.

MIRALLES, 1977 = EURIPIDES. Hipólito. Texto, introducción, nueva traduccíon y notas de Carlos MIRALLES. Barcelona: BOSCH Casa Editorial, 1977.

NAVARRE, O. DIONYSOS: Études sur l'organisation matérielle du théâtre athénien. Paris: Librairie C. Klincksieck, 1895.

PICKARD-CAMBRIDGE, Sir Arthur. The Dramatic Festivals of Athens. 2n. Ed. Oxford: Clarendon Press, 1969.

ROMILLY, J. de. La tragédie grecque. Paris: PUF, 1982.

SANTOS, F. B. dos. O canto na tragédia grega. Aletria, n. 7, pp. 7-14, 2000.

SEGAL, Charles. Interpreting Greek Tragedy. Myth, Poetry, Text. Ithaka/London: Cornell University Press, 1986.

La Musique du Sphinx. Poésie et structure dans la tragédie grecque. Paris: Éd. La Découverte, 1987.

Euripides and the Poetics of Sorrow. Art, Gender, and Commemoration in Alcestis, Hippolytus, and Hecuba. Durham/London: Duke University Press, 1993.

Oedipus Tyrannus. Tragic Heroism and the Limits of Knowledge. Toronto/New York: Twaine Publishers, 1993.

SNELL, Bruno. Scenes from Greek Drama. Berkeley/Los Angeles: University of California Press, 1967.

TAPLIN, Oliver. Greek Tragedy in Action. London: Methuen \& Co, 1978.

VERNANT, Jean-Pierre. Mito e pensamento entre os gregos. Estudos de psicologia histórica. São Paulo: DIFEL/EDUSP, 1973.

WEBSTER, T. B. L. The Greek Chorus. London: Methuen, 1970. 